\title{
Management of Multiple Recession simultaneously with Modified Coronally Advanced Flap
}

\author{
Dr. Harish Kumar Shah, ${ }^{1}$ Dr. Shashi Kant Chaudhary, ${ }^{1}$ Dr. Khushboo Goel, ${ }^{1}$ Dr. Sajeev Shrestha ${ }^{1}$ \\ ${ }^{1}$ Department of Periodontology and Oral Implantology, College of Dental Surgery, \\ B.P. Koirala Institute of Health Sciences, Dharan, Nepal.
}

\begin{abstract}
Gingival recession is one of the aesthetic concern for a beautiful smile. In an aesthetically driven era, root coverage requires consideration of all prognostic factors for successful results. This paper reports a case of treatment of Miller's Class I gingival recession involving multiple teeth. A modified coronally advanced flap procedure was performed. At the postoperative follow-up visits, healing was uneventful. After 9 months, excellent aesthetic result was achieved with complete root coverage. Periodontal health was normal and the patient was satisfied with the result.

Keywords: Gingival recession; modified coronally advanced flap; root coverage.
\end{abstract}

\section{INTRODUCTION}

"Gingival recession" is the exposure of the root surface because of the displacement of the gingival margin apical to cementoenamel junction. ${ }^{1}$ Gingival recession can render patient aesthetically concerned. It can cause tooth sensitivity, cervical abrasion, poor oral hygiene, and increased susceptibility to root caries. For all these reasons, gingival recession requires treatment. It is often difficult to achieve complete and stable root coverage. Therefore, clinically sound knowledge, proper treatment plan, and treatment approaches are needed for good results. ${ }^{2}$ Khocht et al. showed that use of hard toothbrush was associated with recession. ${ }^{3}$ The possible pathogenesis of gingival recession is related to tissue inflammation produced by biofilm accumulation and traumatic brushing.

Evidence shows that a modification of coronally advanced flap alone in many instances results in complete root coverage and is stable over time. ${ }^{4}$ Zucchelli and De Sanctis 2000 technique is one of most effective technique for root coverage in Miller's class I and II recession and it gives excellent aesthetic results. It is simple to perform and can be used to treat for multiple adjacent gingival recession. ${ }^{5}$

\footnotetext{
Correspondence:

Dr. Harish Kumar Shah

Department of Periodontology and Oral Implantology,

College of Dental Surgery, BP Koirala Institute of Health Sciences,

Dharan, Nepal.

email: harishshah46@yahoo.com

Citation

Shah HK, Chaudhary SK, Goel K, Shrestha S. Management of multiple recession simultaneously with modified coronally advanced flap. J Nepal Soc Perio Oral Implantol. 2017;1(2):81-3.
}

\section{CASE REPORT}

A 25-year-old male came to the department of Periodontology and Oral Implantology, College of Dental Surgery, BPKIHS, Dharan, Nepal with a chief complaint of receding gums and sensitivity of teeth for 6 months. Medical history was noncontributory. Hehad a history of aggressive toothbrushing twice a day with hard toothbrush for five minutes with horizontal brushing technique. Clinical examination revealed multiple Miller's Class I gingival recessions on 22, 23 and 24 with $3 \mathrm{~mm}$ of keratinized tissue, recession of 2-3 mm (Figure 1a, 1b) and a thick gingival biotype. Gingival recession was associated with cervical abrasions of 24 (Figure 1b). The recession defect had $1 \mathrm{~mm}$ probing depth with no bleeding on probing of 22, 23 and 24 . The patient was counseled for treatment and patient preferred to go with multiple recession management at same setting. Written and informed consent was taken. Scaling and root planing was done followed by oral hygiene instructions. Following four weeks of phase I therapy, modification of coronally advanced flap (Zucchelli and De Sanctis 2000) technique was carried out. Proper extraoral asepsis with $2 \%$ povidone-iodine was followed by intraoral preprocedural $0.2 \%$

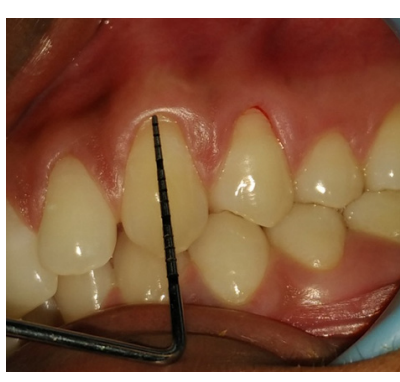

Figure 1a: recession depth of $23=2.5 \mathrm{~mm}$.

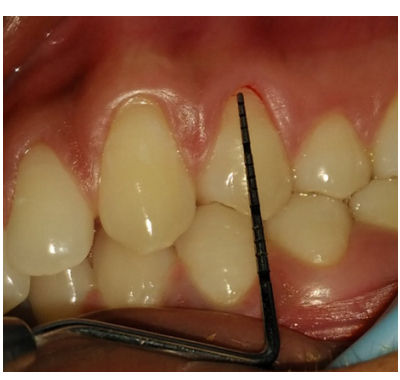

Figure 1b: Recession depth of $24=3 \mathrm{~mm}$. 


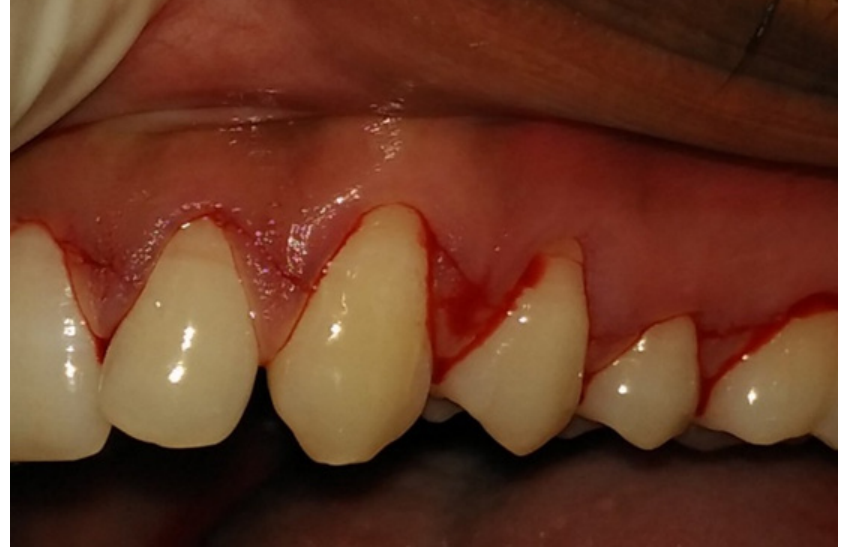

Figure 2a: Oblique incision.

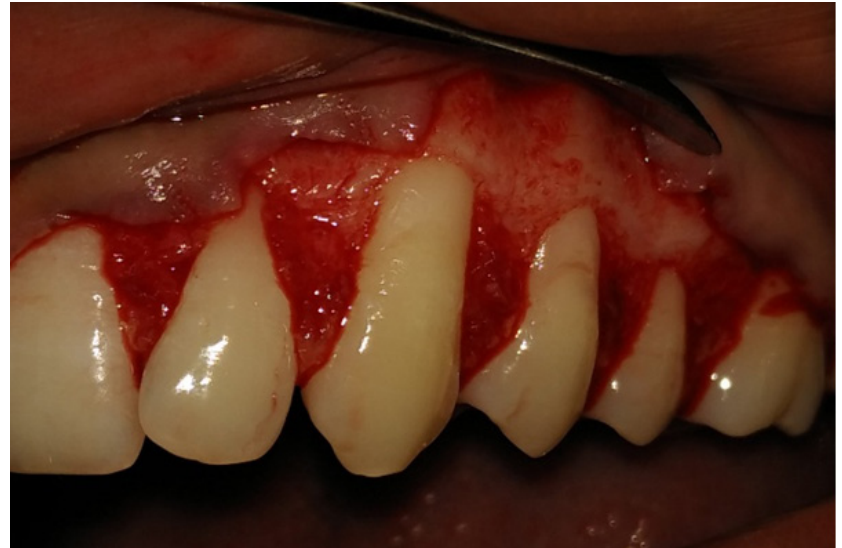

Figure 2b: Split-full-split flap with de-epithelisation.

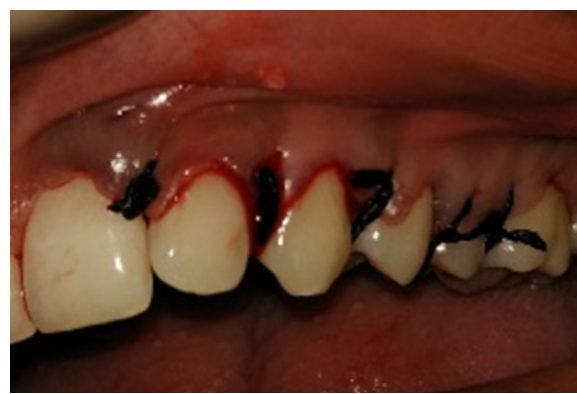

Figure 3a: Interrupted silk sutures placed.

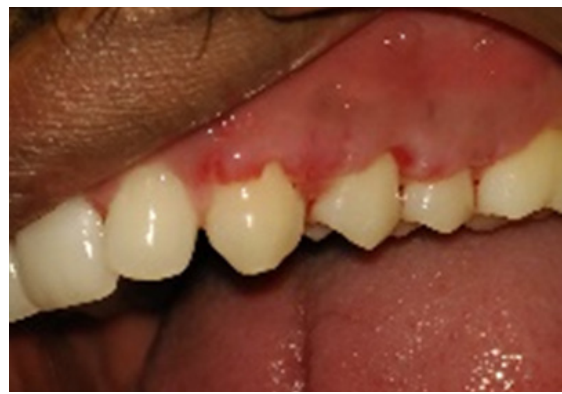

Figure 3b: Sutures removal at 10 days.

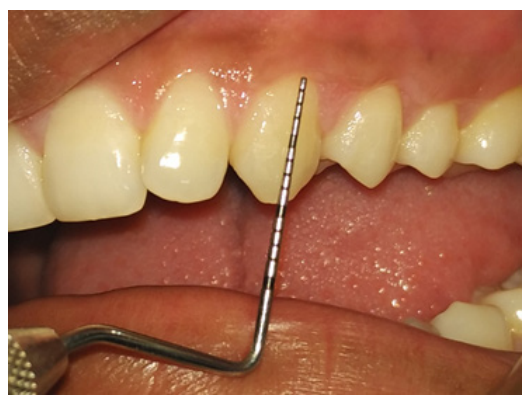

Figure 3c: At nine months. chlorhexidine rinses and then adequate local anaesthesia was administered. Flap design: the horizontal incision of the flap was made with oblique sub-marginal incision in the interdental areas (Figure 2a), which continued as intra-sulcular incision at the recession defects. Flap elevation: the envelop flap was raised with a split-full-split approach in the coronalapical direction; the oblique interdental incisions were carried out keeping the blade parallel to the long axis of the teeth in order to dissect the surgical papilla in a split-thickness. Apical to the level of the root exposure, a fullathickness flap was raised to provide maximum soft tissue thickness of the flap to be positioned coronally over the roots (Figure $2 b$ ). At the most apical portion of the flap, the periosteum was incised and followed by dissection into the vestibular lining mucosa to eliminate all muscle tension. De-epithelization of epithelium in interdental area was done to create connective tissue bed (Figure.2b). The flap was displaced at least $1 \mathrm{~mm}$ coronal to the cemento-enamel junction without tension. Interrupted suturing technique with 3-0 silk was performed (Figure 3a) and after surgery, the patient was prescribed analgesics (Ibuprofen $400 \mathrm{mg}$ every 8 hours) or when needed and 0.2\% chlorhexidine gluconate rinse every 12 hours for 14 days. Postoperative written instructions were given. Sutures were removed after 10 days (Figure.3b). Three weeks after surgery, he was instructed to resume brushing on that side with a soft toothbrush using roll technique carefully. After 9 months (Figure 3c) complete root coverage with normal colour, texture and contouring of gingiva was attained. The patient reported to be completely satisfied with the aesthetical result. His tooth sensitivity had totally disappeared.

\section{DISCUSSION}

One of the most critical factors in the aetiology of hypersensitivity of teeth is the exposure of root surfaces from gingival recession. ${ }^{6}$ The case was performed using the modification of coronally advanced flap given by Zucchelli and de Santis (2000). ${ }^{5}$ In our case report, interrupted suturing technique with 3-0 silk was performed. This technique has less potential for causing wound oedema and impaired circulation. The clinical and aesthetic outcomes of the multiple coronally advanced flap between with or without vertical releasing incisions groups revealed no statistically significant difference in terms of recession reduction and clinical attachment gain. However, the coronally advanced envelope flap showed more sites with complete root coverage, a greater increase in buccal keratinized tissue, fewer postoperative complications and superior aesthetic outcome than the coronally advanced flap with vertical incisions. ${ }^{7,} 8$ A flap thickness of $>0.8 \mathrm{~mm}$ was associated with complete root coverage, while a flap thickness of $<0.8 \mathrm{~mm}$ was associated with partial root coverage. ${ }^{9}$ In our case, recessions were Miller's class I and gingival biotype was thick, this could be reasons for $100 \%$ root coverage and total alleviation of symptoms. 
Thus, Modified coronally advanced flap is very effective for the treatment of gingival recessions. The problems related to aesthetic concern and sensitivity can be managed effectively if proper treatment plan and correct surgical technique are executed.

\section{ACKNOWLEDGEMENT}

We would like to express sincere gratitude to Dr. Shivalal Sharma, Professor, Department of Periodontology and Oral
Implantology, CODS, BPKIHS, Dharan, Nepal for his neverending generous help, keen observation, advice, constant encouragement and constructive criticism without which this work would never have been completed.

\section{REFERENCES}

1. American Academy of Periodontology. Glossary of Periodontal Terms. 4th ed. Chicago: American Academy of Periodontology; 2001.

2. Singh R. Treatment of gingival recession with coronally advanced flap-A case report. J Kathmandu Med Coll. 2012;1(1):29-32.

3. Khocht A, Simon G, Person P, Denepitiya JL. Gingival recession in relation to history of hard toothbrush use. J Periodontol. 1993 Sep;64(9):900-5.

4. Cairo F, Pagliaro U, Nieri M. Treatment of gingival recession with coronally advanced flap procedures: a systematic review. J Clin Periodontol. 2008 Sep;35(8 Suppl):136-62.

5. Zucchelli G, De Sanctis M. Treatment of multiple recession-type defects in patients with aesthetic demands. 2000 Sep;71(9):1506-14.

6. Tugnait A, Clerehugh V. Gingival recession-its significance and management. J Dent. 2001 Aug;29(6):381-94.

7. Zucchelli G, Mele M, Mazzotti C, Marzadori M, Montebugnoli L, De Sanctis M. Coronally Advanced Flap With and Without Vertical Releasing Incisions for the Treatment of Multiple Gingival Recessions: A Comparative Controlled Randomized Clinical Trial. J Periodontol. 2009 Jul;80(7):1083-94

8. Cairo F. Periodontal plastic surgery of gingival recessions at single and multiple teeth. Periodontol 2000. 2017;75(1):296-316.

9. Baldi C, Pini-Prato G, Pagliaro U, Nieri M, Saletta D, Muzzi L, et al. Coronally advanced flap procedure for root coverage. Is flap thickness a relevant predictor to achieve root coverage? A 19-case series. J Periodontol. 1999 Sep;70(9):1077-84. 